\title{
The Attribution of Meaning and Emotion to Song Lyrics
}

William Forde Thompson

University of Toronto

Frank A. Russo

University of Toronto

digital.library.ryerson.ca/object/347

Please Cite:

Thompson, W. F., \& Russo, F. A. (2004). The attribution of meaning and emotion to song lyrics. Polskie Forum Psychologiczne, 9(1), 51-62.

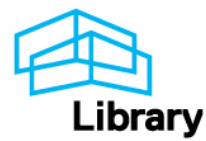




\title{
THE ATTRIBUTION OF EMOTION AND MEANING TO SONG LYRICS
}

\author{
William Forde Thompson, Frank A. Russo \\ University of Toronto, Canada
}

\begin{abstract}
We examined the effect of music on the interpretation of song lyrics. Listeners were presented with sung lyrics, spoken lyrics, or written poetry, and judged the text for emotional valence and meaningfulness. Experiment 1 revealed that, for some songs, music influenced whether lyrics were interpreted as conveying a positive or negative message. Experiment 2 showed that for familiar music, sung lyrics were judged as more meaningful than the same lyrics presented as spoken text, suggesting that personal associations or other significance implied by familiar music are attributed to the accompanying lyrics. In Experiment 3, repeated exposure to unfamiliar songs led to an increase in the perceived meaningfulness of the lyrics. We raise the possibility that music and lyrics become represented in an increasingly integrated manner with increased exposure and familiarity, allowing greater cross-talk between the two media.
\end{abstract}

\section{Introduction}

Songs involve a strong and complex connection between melody and lyrics. Melody and lyrics are often coordinated for overall emotional meaning, points of stress, grouping, expectancy and closure. In some cases prosodic patterns associated with speech influence compositional choices that are made in creating the melodic and rhythmic aspects of a song. Music performers may also express emotions by manipulating the same acoustic variables that are manipulated in emotional speech (for a review, see Juslin \& Laukka, 2003).

Correspondence concerning this article should be addressed to William Forde Thompson, e-mail: b.thompson@utoronto.ca,

This research was supported by a grant to the first author from the Natural Sciences and Engineering Research Council. We thank Aubrey Litvak for technical assistance. 
Although some lyrics are well written, they are not always highly meaningful outside of a musical context. Yet in the context of a song, they may take on unexpected significance. Music invites listeners to search for deeper meaning in lyrics, enhancing the process of semiosis. Whether silly love songs, indulgent songs about personal growth, or naïve political songs, messages conveyed by lyrics seem richer, more profound, more persuasive, and more emotional when embedded in a musical context than when read as straight text (Galizio \& Hendrick, 1972; Iverson, Rees \& Revlin, 1989; Stratton \& Zalanowski, 1994).

For example, it is generally agreed that protest movements of the 60's were greatly influenced by folk and folk-rock music of the time. Yet the lyrics of that music tended to deal with political and social issues in simplistic ways. They conveyed a vague sentiment for political change but rarely if ever articulated a coherent political framework for bringing about such change. In an examination of this phenomenon, Galizio \& Hendrick (1972) presented listeners with four folk songs, each of which had or did not have guitar accompaniment. Lyrics presented in the context of guitar accompaniment were perceived to be more emotionally arousing and persuasive than lyrics presented without guitar accompaniment. The authors proposed that because music listening is a pleasant activity, it creates a temporary mood of compliance toward any recommendations that may be available in an ongoing communication (see also Dabbs \& Janis, 1965).

There are three views on the synchronization of words and song. The first is called assimilation. This position argues that lyrics subserve the music. Assimilationists point out that lyrics are rarely intended to lead an independent life but, rather, presuppose musical completion. According to Suzanne Langer (1957): when words and music come together in song, music swallows words... song is not a compromise between poetry and music... song is music. That is, song lyrics should be interpreted merely as one of the textures of the music.

Another view is independence. In this view, language and music make uneven partners because whereas language is a full-fledged semiotic system with a definable repertory of signs, it is not possible for music to be broken down into meaningful units (Benveniste, 1969). Because music has no identifiable relationship with the semiotics of language, the combination of words and music is destined to fail as an integrated medium.

A third view is interaction. In this view, music and lyrics are partially independent systems with their own rules, but there is enough overlap between them to allow interaction (Gorlée, 1997; Juslin \& Laukka, 2003; Serafine, Crowder \& Repp, 1984). More specifically, overlap in the structural characteristics of prosody and melody might increase the potential for one medium to influence the interpretation of the other medium. Areas of overlap include expectancy and closure, connections between prosody and melody, overlap in rhythm and grouping, and similarities in overall emotional meaning. (for related discussions, see Peretz, Radeau \& Arguin, 2004; Samson \& Zatorre 1991; Besson et al. 1998.)

Because music is temporally patterned, has syntax, creates expectancies, and has nested structure, it connotes meaning and significance, even though it typically makes no actual reference to objects or events in the world. This implied or free-floating meaning might feed into or spill over onto accompanying lyrics.

Figure 1 illustrates the idea schematically as a trickle-down effect. The Figure illustrates how music and lyrics have an expressive shape that unfolds over time. Structural attributes of music such as syntax, rhythm, expectancy, and grouping are often perceived to be meaningful, but their meaning is non-referential. In contrast, the meaning of lyrics relates to definable 
referents. Because music implies meaning but does not refer to specific objects or events, this free-floating meaning may readily become attached to accompanying media such as song lyrics, or film materials.

Music

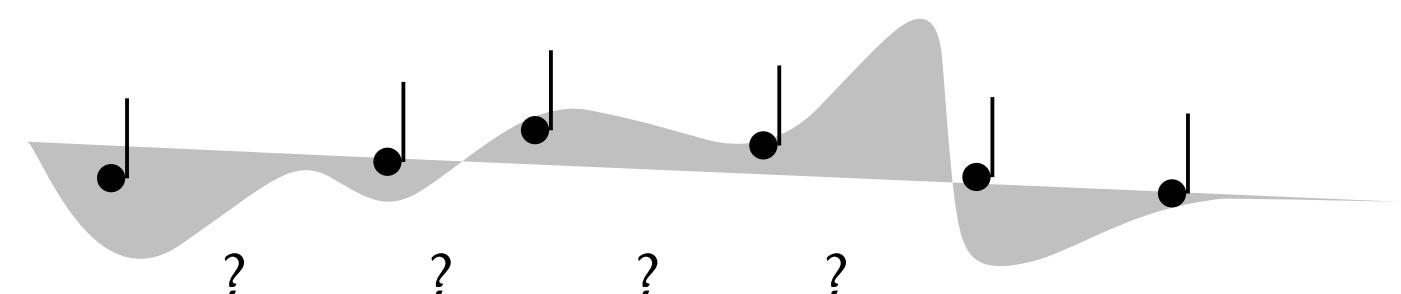

Lyrics

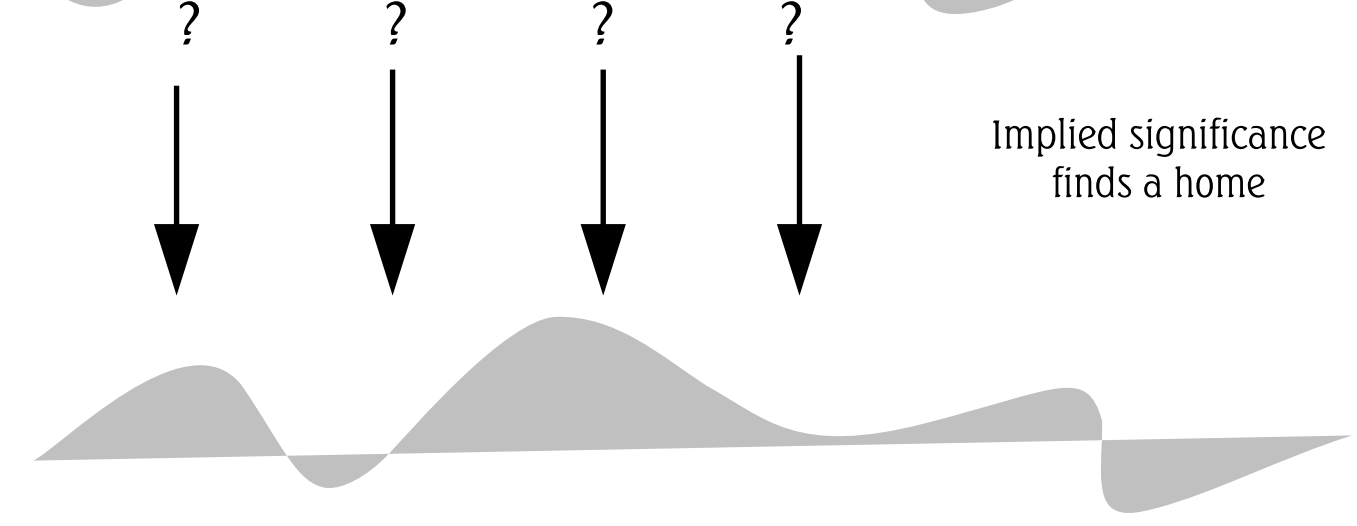

"Welcome to the Hotel California. Such a lovely place"

Figure 1. An illustration of the trickle-down effect, whereby free-floating meaning is attached to accompanying media such as song lyrics

In three experiments, we examined whether music influences responses to song lyrics. We first assessed whether music can manipulate interpretation of the emotional valence of lyrics. We then assessed whether song lyrics are more meaningful and significant when they are embedded in a musical context than when they are evaluated outside of a musical context. Finally, we examined the effects of repeated exposure to unfamiliar songs on the perceived significance of the lyrics.

\section{Experiment 1: Judgments of emotional valence}

The purpose of Experiment 1 was to examine whether the emotional connotation of spoken verbal information can be significantly altered when communicated in the context of a song. It is well known that music is often perceived to convey emotional meaning. For example, emotions conveyed in musical soundtracks significantly influence viewers' interpretation of films (Cohen, 2001; Thompson, Russo, \& Sinclair, 1994). The question addressed in this experiment is whether emotional connotations of music also influence listeners' interpretations of the emotional meaning of accompanying verbal information. 


\section{Method}

Participants. Thirty-four participants were recruited from the University of Toronto community. Participants were assigned to either a music presentation or spoken presentation condition. The age and musical training of participants was well matched across conditions. Participants in the music presentation group included 13 females and 4 males with a mean age of 19.58 years $(S D=2.39)$ and an average of 2.15 years of musical training $(S D=3.23)$. Participants in the spoken presentation group included 13 females and 4 males with a mean age of 19.94 years $(S D=3.21)$ and an average of 2.09 years of musical training $(S D=3.17)$.

Stimuli. Four pieces of pop music were selected that had been hits in the 1970's (all were in the Billboard Top-100 at some point) but were relatively unknown to our sample of participants in the year 2003. These pieces were: 1. "Friend of the Devil" by the Grateful Dead (1970); 2. "Kodachrome" by Paul Simon (1973); 3. "Still the same" by Bob Seger (1978); and 4. "Sundown" by Gordon Lightfoot (1973). For each piece, we selected a continuous excerpt of lyrics that included one verse and the chorus.

A professional musician/producer, Aubrey Litvak, recorded all lyrics in both the sung and spoken conditions. Performances of lyrics were recorded using a Rode NT-2 microphone routed through a Yamaha $01 \mathrm{~V}$ microphone pre-amp into a PC computer running Steinberg Cubase SX. Recordings were digitized at $44.1 \mathrm{Khz}$ using 24-bit ADA conversion. A rendering of the original musical accompaniment to the sung lyrics (e.g., drums, guitar, keyboard) was performed by the musician/producer and was recorded using the same setup. The performance of the sung and spoken versions was mindful of timing - specifically, the onset time of each word was roughly matched across sung and spoken versions of each lyric. In addition, the RMS levels of all recorded lyrics (singing with accompaniment and spoken) were matched to within $2 \mathrm{~dB}$ of maximum and minimum readings. Four pieces of anonymous poetry from the public domain were selected for the text presentation of verbal material. The presentation of audio was realized over Sennheiser HD280 headphones. The presentation of visual text was realized over a computer monitor.

Procedure. Participants in the spoken group rated the valence of both spoken lyrics and written poetry. Participants in the music presentation group rated the valence of lyrics that were sung with musical accompaniment as well as the valence of poetry presented as text on the screen. The trials involving presentations of poetry were identical in spoken and music presentation conditions and served as an anchor so that ratings could be compared across the two conditions. The presentation of poetry and lyrics within conditions was fully randomized.

Participants were asked to rate the extent to which lyrics and poetry conveyed a positive or negative message. Responses were made on a 7-point scale where "1" represented "sad" and "7" represented "happy".

\section{Results and Discussion}

An alpha level of 05 was used for all statistical tests. The primary analysis involved comparing ratings of lyrics when they were sung with music to ratings of lyrics when they were spoken.

Figure 2 shows the effects of music on whether the lyrics were interpreted as conveying a positive or a negative message. The Figure illustrates mean ratings of sung lyrics, spoken lyrics, and written poetry, and illustrates that music influenced the affective valence of the lyrics in different ways depending on the song. In some cases the music increased the sense that the lyrics 
were conveying a positive message, as in Paul Simon's Kodachrome or Greatful Dead's Friend of the Devil, but music had the opposite effect for Gordon Lightfoot's Sundown, and no effect for Bob Seger's Still the same.

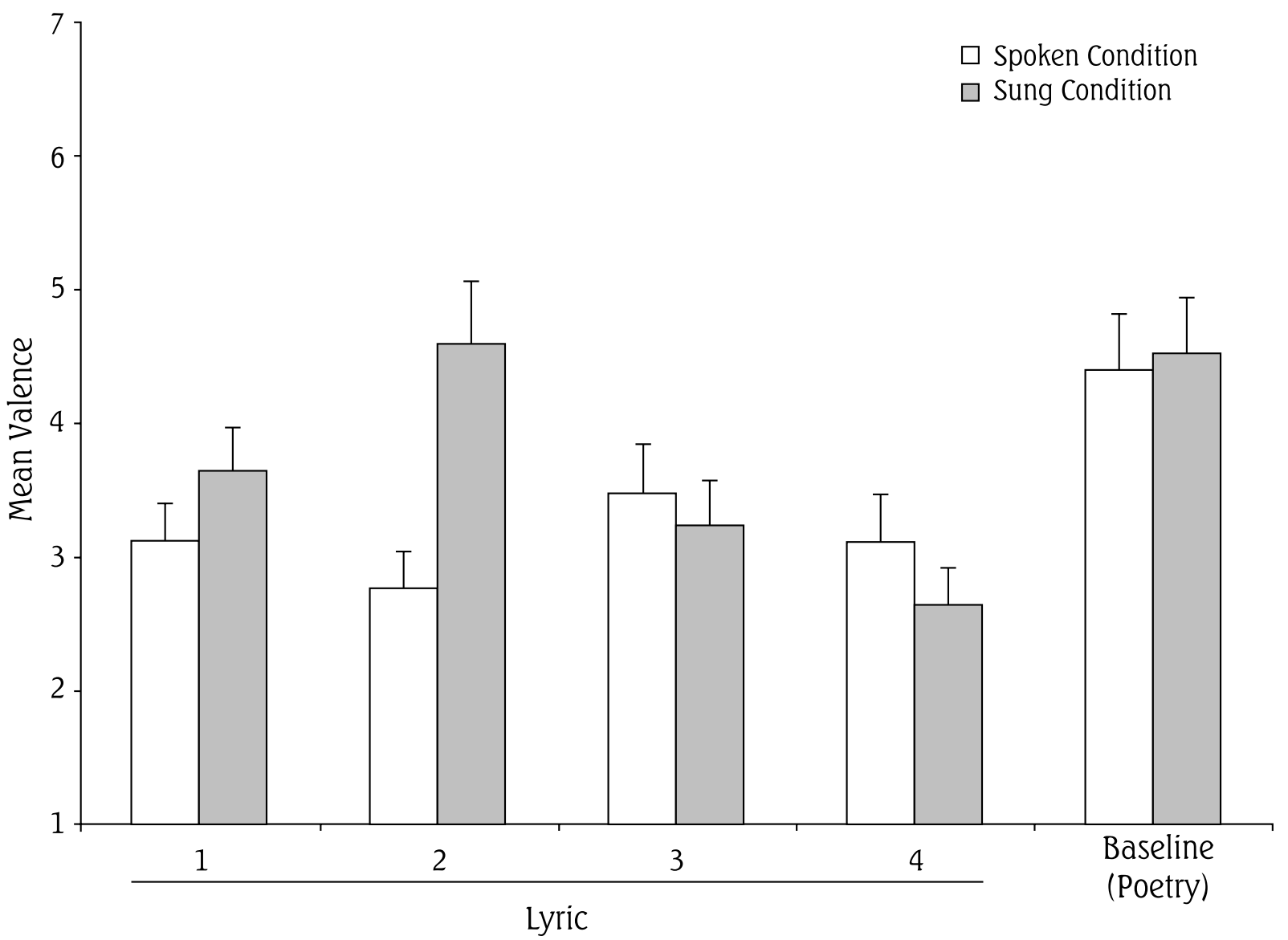

Figure 2. Valence ratings for lyrics and poetry (baseline) in the sung and spoken conditions. Standard errors are shown as error bars

Ratings were subjected to a mixed analysis of variance. The within-subjects variable was lyrics with four levels. The between-subjects variable was presentation mode with two levels (sung or spoken). The effects of lyrics was not significant, $F(3,96)=1.67, n$. .; ; that is, the four lyrics did not differ significantly from each other with regard to perceived valence. There was a marginal effect of presentation mode such that sung lyrics were on the whole perceived to be slightly happier than spoken lyrics, $F(1,32)=3.48, p=.07$.

There was also a significant interaction between lyrics and presentation mode, $F(3,96)=4.15$, $p<.01$. As seen in Figure 2, whereas some lyrics were judged to be more positive when accompanied by music, other lyrics were judged to be less positive when accompanied by music. A Tukey HSD test revealed that the positive influence of music was significant for Lyric $2(p<.05)$. Notably, this song (Paul Simon's Kodachrome) is associated with a striking difference between the emotional message conveyed by lyrics and music. The emotional message conveyed by the lyrics is generally negative, suggesting that there are limits on what can be achieved in life. This negative tone is reflected in the mean rating for the spoken lyrics (the lowest rating among the four spoken lyrics). In contrast, the music that accompanies these lyrics has a fast tempo (132 bpm), is in a major mode, has a syncopated rhythm, and is timbrally bright, thereby conveying a highly positive emotional message. 


\section{Experiment 2: Judgements of meaningfulness}

Experiment 1 illustrated that music can sometimes affect a listener's interpretation of the emotional connotation of verbal information. Experiment 2 was conducted to examine whether music can also influence the perceived meaningfulness of accompanying verbal information.

\section{Method}

Participants. Seventy participants were recruited from the University of Toronto community. Participants were assigned to one of four lyric presentation conditions: 1) spoken / unfamiliar, 2) sung / unfamiliar, 3) spoken / familiar, and 4) sung / familiar. The age and musical training of participants was well matched across conditions. Participants in the spoken / unfamiliar group included 11 females and 6 males with a mean age of 19.8 years $(S D=2.49)$ and an average of 2.97 years of musical training $(S D=3.68)$. Participants in the sung / unfamiliar group included 9 females and 9 males with a mean age of 19.4 years $(S D=1.17)$ and an average of 1.44 years of musical training $(S D=2.58)$. Participants in the spoken / familiar group included 11 females and 6 males with a mean age of 20.0 years $(S D=1.37)$ and an average of 2.19 years of musical training $(S D=3.66)$. Participants in the sung / familiar group included 16 females and 2 males with a mean age of 19.8 years $(S D=1.64)$ and an average of 2.5 years of musical training $(S D=4.41)$.

Stimuli. Lyrics were selected, performed and recorded in the same manner as described in Experiment 1. Poetry was identical to that described in Experiment 1. In addition to the four pieces of music used in Experiment 1, Experiment 2 included four additional pieces from the same musical genre: 1) "Here Comes the Sun" by the Beatles (George Harrison, 1969); 2) "Hotel California" by the Eagles (Don Henley \& Don Felder, 1976); 3) "Wild World" by Cat Stevens (1970); and 4) "Yesterday" by the Beatles (John Lennon \& Paul McCartney, 1965). Unlike the pieces used in Experiment 1, these other pieces were familiar to listeners. Lyrics selected from the four pieces used in Experiment 1 were referred to as unfamiliar and lyrics selected from the new pieces introduced in Experiment 2 were referred to as familiar.

Procedure. Listeners provided ratings of meaningfulness. Judgments of meaningfulness were overall assessments of the significance of the lyrics, for example, whether the ideas presented are informative, artful, novel, generate strong and multiple associations, and are persuasive. Ratings were made on a 7-point scale where a rating of " 1 " represented not very meaningful and a rating of " 7 " represented very meaningful.

After making ratings of meaningfulness, participants in the sung / familiar and sung / unfamiliar conditions were asked to rate the familiarity of each piece (i.e., familiarity prior to arriving at the test session). Familiarity ratings were made on a scale from 1 to 4 , where a rating of 1 meant "l've never heard this song before," a rating of 2 meant, "l think I might have heard it once or twice before," a rating of 3 meant "l am somewhat familiar with this song," and a rating of 4 meant "l am very familiar with this song." Mean ratings for familiar songs ( $M=3.13, S E=0.19$ ) were much higher than mean ratings for unfamiliar songs $(M=1.51, S E=0.19), F(1,34)=$ $36.79, p<.0001$. 


\section{Results and Discussion}

The primary analysis involved a $2 \times 2 \times 4$ mixed design ANOVA with familiarity (familiar or unfamiliar) and presentation mode (sung with music or spoken) as between-subjects variables and lyric (4 levels) as the within subject variable. For both familiar and unfamiliar songs, we were interested in whether ratings of lyrics when they were sung with music were higher than ratings of lyrics when they were spoken. Figure 3 illustrates the effect of music on the perceived meaningfulness of lyrics. There was a main effect of familiarity on meaningfulness, $F(1,66)$ $=15.34, p<.001$, with lyrics from familiar songs judged to be more meaningful $(M=4.05$, $S E=.27)$ than lyrics from unfamiliar songs $(M=3.02, S E=.27)$. The main effect of presentation mode was not significant, but there was a significant interaction between familiarity and presentation mode, $F(1,66)=4.84, p<.05$. As seen in Figure 3 , music enhanced the perceived meaningfulness of lyrics only for familiar songs. Separate analyses of data for familiar and unfamiliar conditions confirmed that there was a significant effect of presentation mode for familiar songs, $F(1,33)=6.08, p<.05$, but not for unfamiliar songs, $F(1,33)<1.0$, ns.

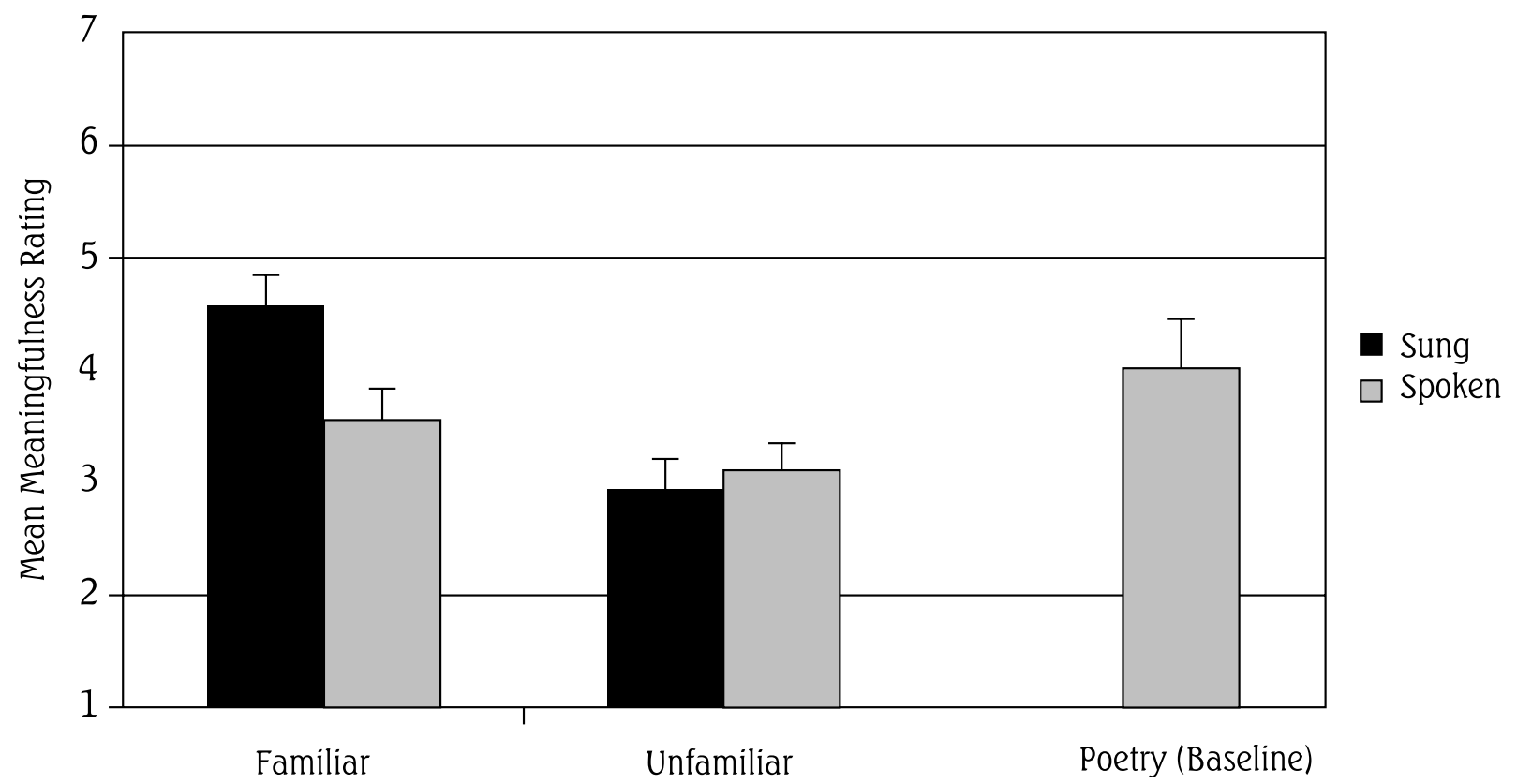

Figure 3. Meaningfulness ratings for lyrics and baseline poetry in all conditions of Experiment 2. Standard errors are shown as error bars

One interpretation of this interaction is that listeners had personal associations with the familiar music, for example, a particular summer vacation or party. Such personal associations with the music may have been conflated with the meaning of the lyrics themselves. A second possibility is that repeated exposure to music caused the music and lyrics to be represented in a more tightly integrated manner, which allowed greater cross-talk or mutual influence between the two media. A third possibility is that the familiar music was more predictable and therefore less distracting than the unfamiliar music. That is, selective attention to the meaning of lyrics may be easier for familiar music than for unfamiliar music. 
If the first hypothesis is correct - that listeners confuse personal associations with the meaning of the lyrics - then mere exposure to unfamiliar songs in a neutral lab condition should have no or little effect on ratings of meaningfulness. Exposing listeners to music should increase familiarity, but it should not give rise to strong personal associations with that music. If the second or third hypothesis is correct, then increasing familiarity to music through mere exposure should lead to an increase in ratings of meaningfulness. Experiment 3 was conducted to evaluate this possibility.

\section{Experiment 3: Effects of repeated exposure}

Experiment 2 indicated that verbal information is perceived to be more meaningful when it is expressed in song than when it is merely spoken, but this effect was limited to familiar songs. Experiment 3 was conducted to evaluate whether the perceived meaningfulness of song lyrics increases following increased exposure to the song.

\section{Method}

Participants. Thirty-seven participants were recruited from the University of Toronto community. Eighteen participants rated the lyrics of the unfamiliar song set after no previous exposure (no-exposure group); nineteen different participants rated the lyrics of the unfamiliar song set after repeated exposure to the songs (repeated-exposure group). Data for the no-exposure group were the same as those described for the unfamiliar sung condition in Experiment 2.

Participants in the no-exposure group are described in Experiment 2. Participants in the repeated-exposure group were well matched to the latter group, and included 15 females and 4 males with a mean age of 19.42 years $(S D=2.34)$ and an average of 2.45 years of musical training $(S D=3.24)$.

Procedure. Listeners provided ratings of meaningfulness, as in Experiment 2. In the exposure phase, listeners read magazines or books while the unfamiliar music samples were played repeatedly in blocked random order in the background. In total, each participant was exposed to five repetitions of each song prior to the test trials.

Stimuli. The lyrics presentation was identical to that described for the unfamiliar sung condition of Experiment 2. Visually presented poetry was also presented to both groups as an anchor for their other judgments.

\section{Results and Discussion}

The primary analysis involved comparing mean ratings of lyrics by the no-exposure and repeatedexposure groups. Figure 4 compares ratings of the meaningfulness of lyrics of unfamiliar music by the no-exposure group ( $M=2.94, S E=0.24$ ) with ratings by the repeated-exposure group ( $M$ $=3.66, S E=0.23$ ). The Figure illustrates that repeated exposure to the songs led to an increase in the perceived meaningfulness of the lyrics, $F(1,35)=4.66, p<.05$. In other words, increasing familiarity through repeated exposure enhanced the perceived significance of lyrics. 


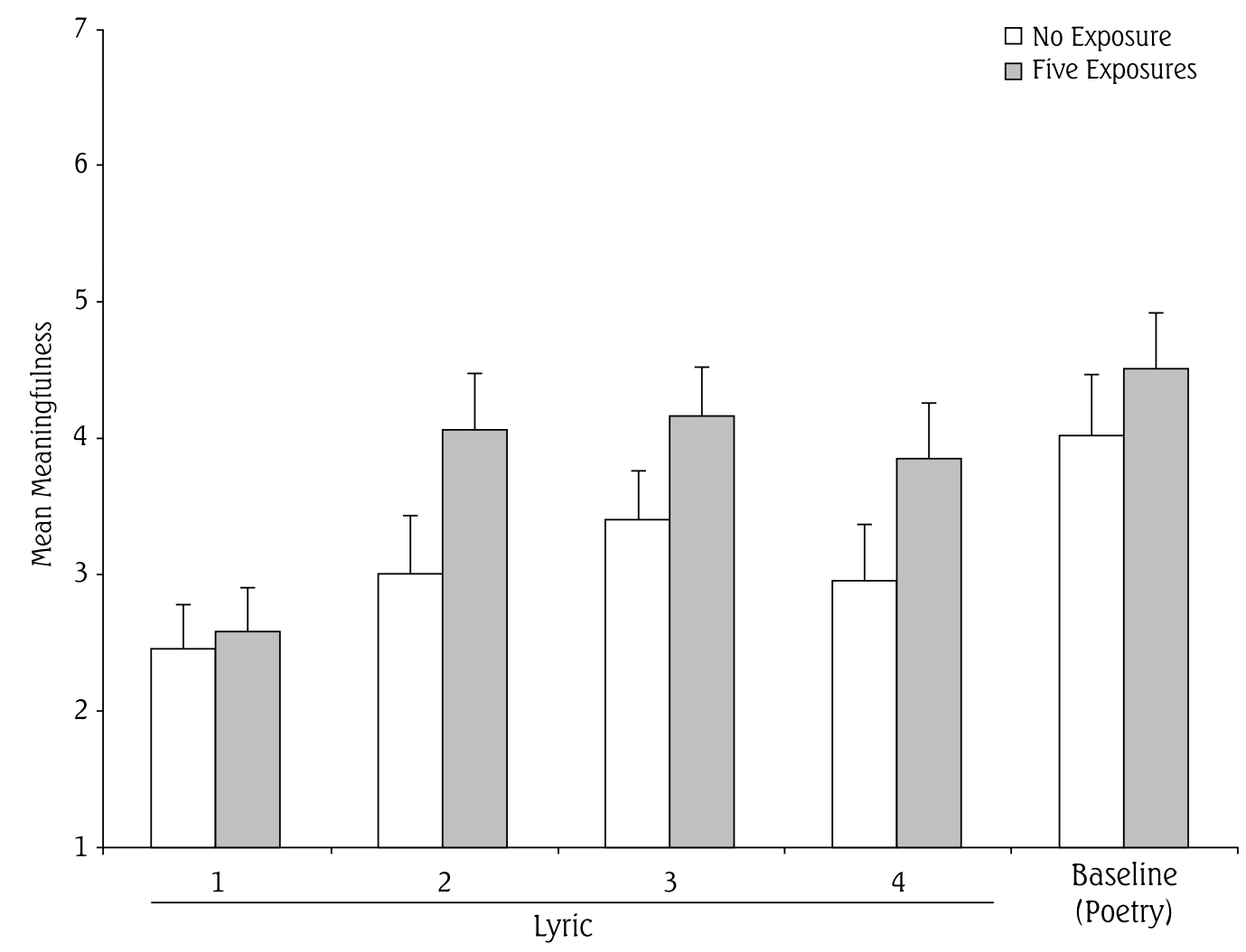

Figure 4. Ratings of the meaningfulness of the lyrics of unfamiliar music and poetry (baseline) after the first exposure and after repeated exposure. Standard errors are shown as error bars

\section{General Discussion}

The results of this study indicate that music influences the attribution of meaning and emotion to song lyrics. First, Experiment 1 indicated that a musical context can influence the overall affective valence attributed to accompanying lyrics. Thus, lyrics accompanying sad music are more likely to be interpreted as communicating a negative message, whereas lyrics accompanying joyful or happy music are more likely to be interpreted as communicating a positive message. Second, for familiar songs, listeners attributed greater overall significance and meaning to lyrics if they were sung with music than if they were merely spoken. Third, repeated exposure to songs increased the perceived meaningfulness of accompanying lyrics. This latter finding contradicts the view that the link between familiarity and perceived meaningfulness can be explained entirely by personal associations. For if this were the case, one would not expect repeated-exposure to unfamiliar songs in laboratory conditions to influence the perceived meaningfulness of the accompanying lyrics.

Two other possibilities exist. First, repeated exposure may promote a more integrated representation of music and lyrics (Crowder, Serafine \& Repp, 1990; Serafine, Crowder \& Repp, 1984; Serafine, Davidson, Crowder \& Repp, 1986). Stronger integration of music and lyrics, in turn, might allow greater transfer of implied significance from music to accompanying lyrics. Figure 5 illustrates the process. When songs are unfamiliar, musical and verbal textures are likely to be perceived as somewhat distinct, independent media. The degree of perceived independence will, 
of course, depend on the extent to which the songwriter coordinated common elements of music and speech. On the whole, however, music and lyrics should be perceived as more distinct for unfamiliar songs than for familiar songs.

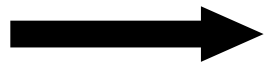

Increasing exposure
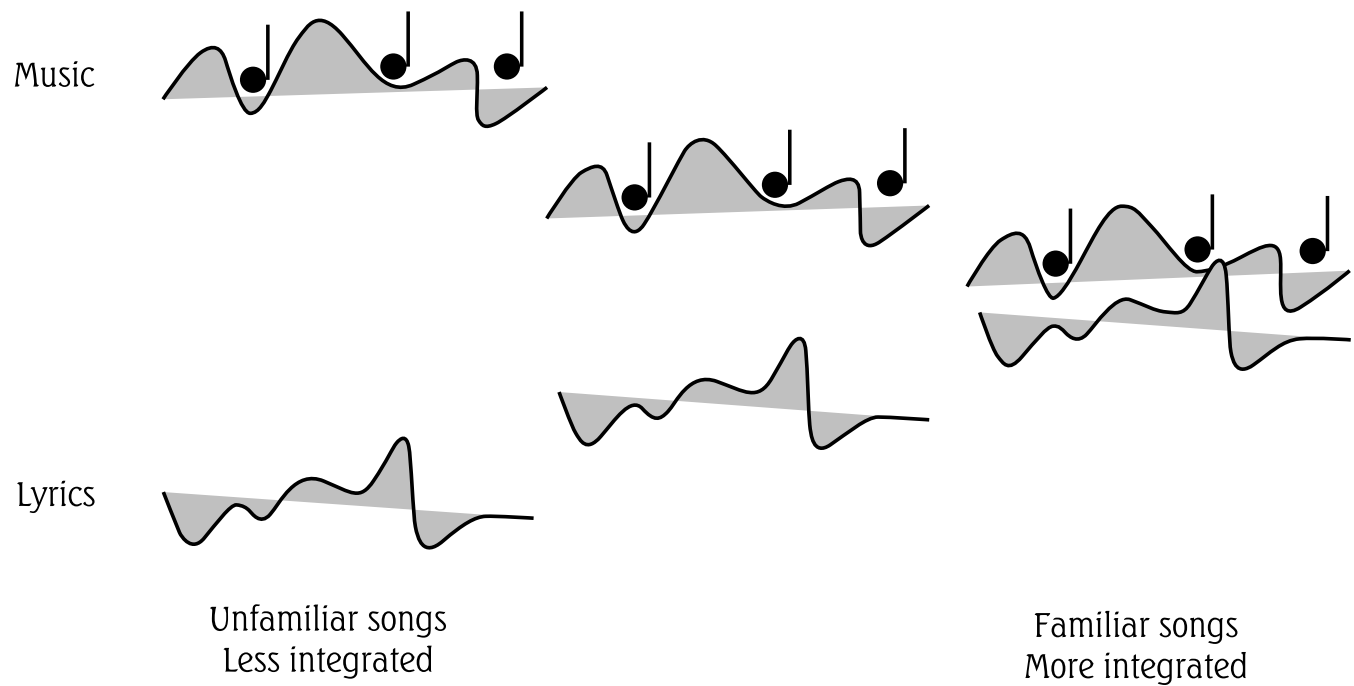

Familiar songs

More integrated

Figure 5. An illustration of the effect of repeated exposure on the degree of integration between music and lyrics, and the attribution of non-referential musical meaning to the accompanying lyrics

With repeated exposure, music and lyrics sound more and more like they "go together" and this increased integration increases the likelihood that free-floating (non referential) significance implied by the music will be attributed to the accompanying lyrics through a trickle-down effect (see also Figure 1). The process may be experienced in the following way: with greater familiarity, the musical texture is increasingly perceived as a fitting dramatic backdrop for the accompanying lyrics, aptly emphasizing, elaborating and clarifying those lyrics and thereby magnifying their apparent significance.

A second possibility is that ratings of meaningfulness are merely related to the amount of verbal information extracted from the lyrics. It can be difficult for listeners to understand lyrics in unfamiliar music because words are sometimes obscured in song, particularly during passages that involve a fast tempo, dense texture, or large changes in pitch. Repeated exposure to music may have allowed listeners to hear more of the words in the lyrics. Conversely, listeners may have found it easier to ignore the accompanying music when it was familiar because familiar music is more predictable and requires fewer cognitive resources than unfamiliar music. By increasing the amount of verbal information extracted from the lyrics (the "signal") and reducing the potential distraction arising from the accompanying music (the "noise"), it may have been easier for listeners to interpret the meaning of the lyrics. In other words, increases in familiarity may be associated with a higher functional signal (lyrics) to noise (music) ratio, leading to an enhanced ability to interpret the lyrics. 
Although our study was not designed to disentangle these two hypotheses, the latter possibility implies that lyrics should be perceived as more meaningful when presented in isolation than when presented with potentially distracting music ("noise"). However, we observed the opposite effect in Experiment 2. Familiar lyrics were perceived as significantly more meaningful when they were sung in a musical context than when they were spoken in the absence of music. Thus, the effects of familiarity to songs on the perceived meaningfulness of accompanying lyrics cannot be explained solely in terms of the amount of verbal information extracted from the lyrics.

To conclude, music can influence whether lyrics convey a positive or negative message, it can affect the perceived meaningfulness of lyrics for familiar songs, and repeated exposure to a song increases the perceived meaningfulness of the lyrics. Such effects may occur through a trickle-down process that is enhanced through repeated exposure to the music.

\section{REFERENCES}

Benveniste, E. (1985). The semiology of language. In: R. E. Innis (Ed.) Semiotics: An Introductory Anthology, Bloomington: Indiana University Press, 226-246.

Besson, M., Faïta, F., Peretz, l., Bonnel, A-M., Requin, J. (1998). Singing in the brain: independence of lyrics and tunes. Psychological Science, 9, 494-498.

Cohen, A. (2001). Music as a source of emotion in film. In: P. Juslin, J. Sloboda (Eds.) Music and Emotion: Theory and Research (pp. 249-274). Oxford: Oxford University Press.

Crowder, R., Serafine, M. L., Repp, B. (1990). Physical interaction and association by contiguity in memory for the words and melodies of songs. Memory \& Cognition, 18, 469-476.

Dabbs, J. M., Janis, I. L. (1965). Why does eating while reading facilitate opinion change? - An experimental inquiry. Fournal of Experimental Social Psychology, 1, 133-144.

Galizio, M., Hendrick, C. (1972). Effect of music accompaniment on attitude: The guitar as a prop for persuasion. Fournal of Applied Social Psychology, 2, 350-359.

Gorlée, D. L. (1997). Intercode translation: Words and music in opera. Target, 9, 235-270.

Iverson, J., Rees, H., Revlin, R. (1989). The effect of music on the personal relevance of lyrics. Psychology: A Fournal of Human Behaviour, 26, 15-22.

Juslin, P. N., Laukka, P. (2003). Communication of emotions in vocal expression and music performance: Different channels, same code? Psychological Bulletin, 129, 770-814.

Langer, S. (1957). Philosophy in a New Key: A Study in the Symbolism of Reason, Rite, and Art. Cambridge, MA: Harvard University Press.

Peretz, l., Radeau, M., Arguin, M. (2004). Two-way interactions between music and language: Evidence from priming recognition of tune and lyrics in familiar songs. Memory \& Cognition, 32, 142-152.

Samson, S., Zatorre, R. J. (1991). Recognition memory for text and melody of songs after unilateral temporal-lobe lesion: evidence for dual encoding. Fournal of Experimental Psychology: Learning, Memory \& Cognition, 17, 793-804.

Serafine M. L., Crowder R. G., Repp B. H. (1984). Integration of melody and text in memory for songs, Cognition, 16, 285-303. 
Serafine, M. L., Davidson, J., Crowder, R., Repp, B. (1986). On the nature of melody-text integration in memory for songs. Fournal of Memory and Language, 25, 123-135.

Stratton, V. N., Zalanowski, A. H. (1994). Affective impact of music vs. lyrics. Empirical Studies of the Arts, 12, 173-184.

Thompson, W. F., Russo, F. A., Sinclair, D. (1994). Effects of underscoring on the perception of closure and intensity in film excerpts. Psychomusicology, 13, 9-27. 